\title{
Injured Neurons in the Olfactory Bulb of the Adult Rat Grow Axons along Grafts of Peripheral Nerve ${ }^{1}$
}

\author{
BETH FRIEDMAN AND A. J. AGUAYO
}

Neurosciences Unit, Department of Neurology, The Montreal General Hospital and McGill University, 1650 Cedar Avenue, Montreal, Quebec, Canada H3G 1 A4

\begin{abstract}
Certain neurons in the central nervous system (CNS) of adult mammals extend axons for several $\mathrm{cm}$ along peripheral nerve grafts inserted into the brain or spinal cord. It is not clear, however, if these nerve cells constitute a special population or are examples of a general capacity of the injured mammalian CNS to regrow processes under these experimental conditions. Furthermore, because the new axons could originate by collateral sprouting from uninjured neurons, it is important to prove that the interruption of a central axonal projection can be followed by extensive fiber regrowth from the damaged neurons. In this anatomical study, we examined whether: (1) nerve cell type; and (2) axotomy, influence CNS axon regrowth along peripheral nerve grafts. For this purpose, we grafted segments of sciatic nerve into the olfactory bulb $(O B)$ of adult rats and used combinations of neuroanatomical tracers (horseradish peroxidase and the fluorescent dyes True Blue and Nuclear Yellow) to investigate axonal regrowth from the different neurons that normally populate the $O B$. We demonstrate that $O B$ axons extending along peripheral nerve grafts originate from mitral and tufted cells near the graft tip, rather than from the smaller OB neurons (periglomerular, short axon, and granule cells). Most of the mitral and tufted cells that extend new axons in grafted peripheral nerve segments lose their normal projections through the lateral olfactory tract because of axotomy at the time of grafting. Neuronal type, damage, and proximity to the graft appear to be prerequisites of this regenerative response from the $O B$.
\end{abstract}

When axons are severed, neuronal connectivity may be recstab lished by the regrowth of damaged cell processes (Cajal, 1928; Sperry, 1941; Purves et al., 1981) or the extension of collateral branches from intact neurons (Edds, 1953; Raisman, 1977). However, while many cut axons regrow for long distances in the peripheral nervous system (PNS), indigenous adult peripheral and central neurons, as well as transplanted fetal nerve cells, fail to elongate axons for more than a few millimeters through the injured brain or

Received July 27, 1984;

Accepted October 3, 1984

\footnotetext{
${ }^{1}$ We thank Carol Morgan and Margaret David for technical assistance and Jane Trecarten for preparation of the illustrations. Abstracts of this work have been published (Friedman, B., and A. J. Aguayo (1982) Soc. Neurosci. Abstr. 8: 199; Friedman, B., and A. J. Aguayo (1983) Soc. Neurosci. Abstr. 9: 770) This work was supported by grants from the Medical Research Council of Canada and The Multiple Sclerosis Society (Canada).

${ }^{2}$ To whom correspondence should be directed.
}

spinal cord of adult mammals (Cajal, 1928; Aguayo et al., 1982a, b; Björklund and Stenevi, 1984). This failure of damaged axons to grow within the adult central nervous system (CNS), attributed by Cajal (1928) to an "inhospitable" CNS environment, has been reassessed in recent experiments in mature rodents where grafts of CNS glia or segments of peripheral nerve were inserted along the path of peripheral and central axons (Richardson et al., 1980; Aguayo et al., $1982 \mathrm{a}, \mathrm{b})$. While there was little growth of PNS fibers along CNS glial grafts (Aguayo et al., 1978; Weinberg and Spencer, 1979), the axons of nerve cells from the adult and fetal CNS (Aguayo et al., 1984) extend for several $\mathrm{cm}$ through peripheral nerve grafts. Thus, conditions in the PNS nerve segments, perhaps enhanced by nerve transection, axonal degeneration, and the proliferation of sheath cells (Aguayo et al., 1983) can result in a lengthy growth of axons from different CNS neurons.

The cells of origin of the axons that innervate these PNS grafts have been categorized with various anterograde and retrograde anatomical tracers (Richardson et al., 1984), as well as immunohistochemical (Bray et al., 1985), histofluorescent (Aguayo et al., 1984), and electrophysiological (Munz et al., 1985; Vidal-Sanz et al., 1984) techniques. Although the number and distribution of the neurons giving rise to the new axons varied in the different experiments, there are some consistent findings. (1) Most of the neurons are near the site of injury and grafting (David and Aguayo, 1981; Benfey and Aguayo, 1982), but some cells several $\mathrm{cm}$ away also innervate PNS grafts Richardson et al., 1984). (2) Thus far, the largest neuronal populations have been associated with the insertion of PNS grafts into the brainstem (Munz et al., 1985) and the retina (So and Aguayo, 1985), while similar implants in the cerebral cortex result in fewer cells extending axons along grafts (Benfey and Aguayo, 1982; Buenger and Aguayo, 1983). (3) The neurons that grow axons into PNS grafts vary in shape, size, electrophysiological properties, and also in their transmitter immunoreactivity and histofluorescence (Aguayo et al., 1983; Munz et al., 1985; Aguayo et al., 1984; Benfey et al., 1985). (4) Some central axons can grow along PNS grafts for distances equivalent to those of many of the long projection and association fibers in the normal brain and spinal cord (Benfey and Aguayo, 1982; Aguayo et al., 1983).

In the present experiments, aimed at determining if cell type and axotomy influence the growth of central axons into PNS grafts, we grafted segments of autologous peripheral nerve into the dorsum of the adult rat olfactory bulb $(\mathrm{OB})$ and studied local neuronal responses to injury and grafting. The $O B$ was selected because of the following. (1) It has a stereotyped organization. The intrinsic $O B$ neurons are either locally confined small cells with short or no axons (the periglomerular, short axons, and granule cells) or the larger mitral and tufted projection neurons with long axons that extend in the lateral olfactory tract (LOT) for several millimelers (Price and Powell, 1970a, b; Shepherd, 1972; Haberly and Price, 1978). (2) The capacity of $\mathrm{OB}$ nerve cells to regenerate axons after injury is unknown in spite

of the clear demonstration that their afferent neurons in the primary 
sensory epithelium of the nasal mucosa divide and differentiate throughout life (Graziadei and Graziadei, 1980). The specific objective of this anatomical study was to investigate: (1) if $\mathrm{OB}$ neurons grow axons into PNS grafts; (2) the type and location of such OR neurons; and (3) if the mitral and tufted cells regrow axons along these grafts, do they: (a) maintain their normal projections through the LOT; $(b)$ lose their LOT projections as a consequence of a gradual axonal retraction; or (c) undergo axotomy at the time of grafting? For these purposes, we used the retrogradely transported tracers horseradish peroxidase (HRP) and the fluorescent dyes True Blue (TB) and Nuclear Yellow (NY) to locate the source of the axons in the grafl and LOT. Because TB and NY fluoresce in different colors, have distinct cellular localizations (Kuypers et al., 1980), and are transported equally within axons (Jeffrey et al., 1981), we investigated possible single and double projections from $O B$ neurons by applying, several months after grafting, one dye to the graft and another to the LOT (Fig. 1). The retraction or severance of LOT projections from $O B$ neurons extending axons into these grafts was examined by varying the time of application of these dyes to the graft and the LOT.

\section{Materials and Methods}

\section{Nerve graft insertion}

In 50 adult Sprague-Dawley rats of both sexes, anesthetized with chloral hydrate (42 mg/100 gm of body weight), a $2-$ to $3-\mathrm{cm}$-long segment of the sciatic nerve was removed from the right leg and transplanted (David and Aguayo, 1981) to the surgically exposed dorsal surface of one $O B$ of the same animal (Fig. 1). The graft was sutured to the dura and with a glass micropipet one tip of the nerve graft was inserted into the bulb, while the other end of the graft was either tied off or similarly inserted into the contralateral OB (Fig. 2)

\section{Anatomical tracing methods}

\section{HRP labeling}

In 15 rats, we searched for the source of axons growing into PNS grafts inserted into the dorsum of the OB. From 2 to 6 months after grafting, the PNS grafts were dissected and cut 0.5 to $1 \mathrm{~cm}$ from their $\mathrm{OB}$ insertion (Fig. 1). The cut end of the graft was placed for $1 \mathrm{hr}$ on a Gelfoam pledget (Upjohn) soaked in a $20 \%$ solution of HRP (Sigma-type VI). Animals were perfused with saline and gluteraldehyde $48 \mathrm{~h}$ later, and $40-\mu \mathrm{m}$-thick sections of the brain were cut on a cryostat and collected on glass slides. Sections

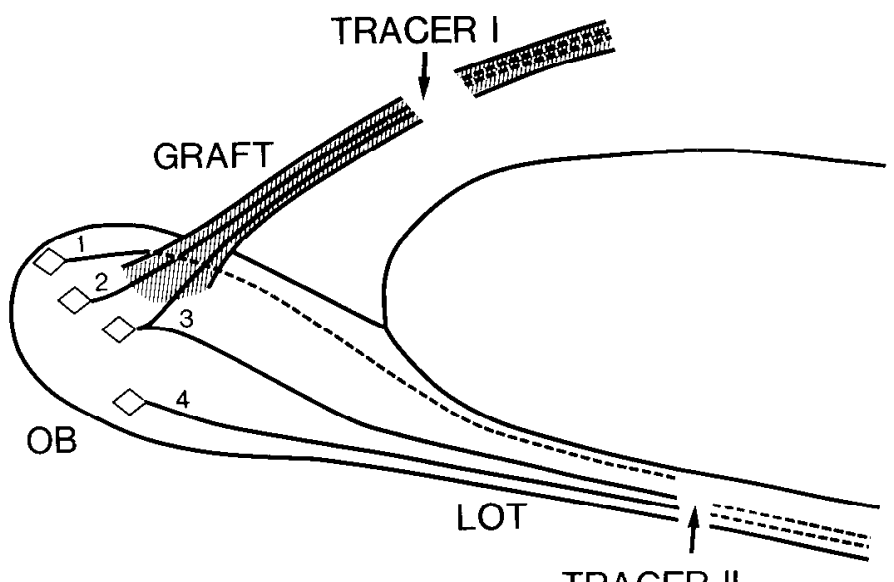

Figure 1. Schematic representation of peripheral nerve graft insertion into the $O B$ and of sites of tracer application to the graft and to the LOT. The sequential application of different tracers to the graft and the LOT retrogradely labels $\mathrm{OB}$ neurons and distinguishes between four possible effects of grafting on the axons arising from the projection neurons of the $\mathrm{OB}$, represented here by neurons 1 to 4 : (1) neuron loses LOT axon because of axotomy during grafting; (2) neuron extends new axon into the graft but not into the LOT; (3) neuron projects into both the graft and the I. OT; (4) neuron maintains its projection into the LOT and does not grow an axon into the graft. of the $\mathrm{OB}$ were reacted with tetramethylbenzidine (Mesulam, 1978), counterstained with thioniri, dehydraled, and coverslipped. Segments of the extracranial portion of the graft were embedded in plastic, and $0.5-\mu \mathrm{m}$ transverse sections were stained with toluidine blue.

\section{Double labeling with fluorescent dyes}

Thirty-two rats were examined by these techniques (Bentivoglio et al. 1979; Jeffrey et al., 1981; Luskin and Price, 1982) to determine if OB neurons extending axons into these grafts: (1) maintained projections into the LOT (see "Group I" below); (2) were injured at the time of grafting (see "Group II" below). Two groups of experiments were done. In group I, several months after grafting, different fluorescent dyes were applied to the graft and the LOT within $48 \mathrm{~h}$ of each other. In group II, a fluorescent dye was applied to the LOT on the same day as grafting and a second fluorescent dye was applied to the graft 3 to 6 weeks later.

Group I. In 15 rats, a gelfoam (Upjohn) pledget soaked in an aqueous solution of 2 to $4 \%$ TB (GMbh \& Co-KG Makromoleculare Chemie) or 3\% NY (Hoechst AG, S769121) was applied for $1 \mathrm{~h}$ to the graft 2 to 6 months after grafting; $48 \mathrm{~h}$ later, the ipsilateral LOT was exposed surgically using a temporal approach modified from Powell et al. (1965). A gelfoam pledget soaked in the second dye was inserted into a transection made in the LOT at the level of the anterior piriform cortex, within $5 \mathrm{~mm}$ of the caudal edge of the bulb (Fig. 1). Rats were sacrificed $48 \mathrm{~h}$ after the application of fluorescent dye to the LOT and perfused transcardially with a fixative solution of formaldehyde $(6 \%)$ and gluteraldehyde $(0.01 \%)$ followed by the same fixative with $3 \%$ sucrose (modified from Sawchenko and Swanson, 1981). Sections $20 \mu \mathrm{m}$ thick were cut on a cryostat, covorslipped with Di n butylphthalate xylene, examined, and photographed under epifluorescent illumination $(360$ $\mathrm{nm}$ ). In five of these animals, the $\mathrm{OB}$ was also stained with thionin to search for neuronal loss and atrophy due to direct darnage to the cell somata or retrograde degeneration caused by axotomy.

Group /I. In 17 rats, different dyes were applied in two stages. Immediately after gratting the PNS segment into the OB, the ipsilateral LOT was cut within $5 \mathrm{~mm}$ of the bulb, and a small Gelfoam pledget soaked in 2 to $4 \%$ TB was left in contact for at least 3 weeks with the transected LOT to label those mitral and tufted cells whose axons to the LOT were not severed in the $\mathrm{OB}$ by the grafting procedure (Fig. 1). From 3 to 6 weeks later, a second dye, NY, was applied in a 3\% solution to the cut peripheral end of the PNS graft for $1 \mathrm{hr}$. These animals were reanesthetized and sacrificed $48 \mathrm{~h}$ later and the tissues processed as above.

The following precautions were taken to avoid spurious labeling of neurons: (1) tracers were always applied to the peripheral graft tip 0.5 to $1.0 \mathrm{~cm}$ from the end inserted into the $\mathrm{OB}$; (2) to avoid tracer diffusion into the surrounding tissues at the time of labeling, the dissected end of the graft was placed on a Parafilm sheath and surrounded by petroleum jelly.

\section{Reliability of the tracing methods used}

In three rats with grafts bridging both $\mathrm{OBs}$, the graft was transected once at the midportion 2 or 3.5 months after grafting and the stumps placed in contact for $1 \mathrm{hr}$ with TB to retrogradely label neurons in both bulbs; $48 \mathrm{hr}$ later, the graft stump leading to only one of the bulbs was crushed with fine forceps whose tips were previously frozen in liquid nitrogen, and NY was applied to both the crushed and uncrushed graft stumps to determine if the transporting of this second label is impaired when axonal continuity along the graft is disrupted by crush. Finally, to establish if the prolonged application of TB to axons severed in the LOT results in the retrograde labeling of most mitral cells in the $O B$, we placed, for 3 weeks, Gelfoam pledgets soaked with $3 \%$ TB in contact with the rostral stump of the LOT, approximately 5 to $7 \mathrm{~mm}$ caudal to the OB ( $n=3$ bulbs). The number of labeled mitral cells in each bulb was determined from $10(20-\mu$ m-thick $)$ coronal sections $300 \mu \mathrm{m}$ apart. These sections were counterstained with thionin to determine the ratio of labeled to unlabeled cells in each $\mathrm{OB}$.

\section{Results}

At autopsy, the ends of the grafts were in gross continuity with the dorsal surface of the grafted OBs (Figs. 2A and 3). Graft crosssections, examined by light microscope, contained variable numbers of axons ensheathed by Schwann cells (Fig. 2B).

\section{HRP labeling experiments}

The purpose of these studies was to document the number, type, and distribution of the neurons that grew axons into these grafts. Examination of 15 rats with PNS grafts bridging both OBs revealed 
Figure 2. A, Peripheral nerve graft links both OBs. Dorsal view 2 months after grafting. Bar, $1 \mathrm{~mm}$. B, Cross-section $(0.5 \mu \mathrm{m})$ through extracranial portion of a graft shows thinly myelinated axons. Bar, $10 \mu \mathrm{m}$.
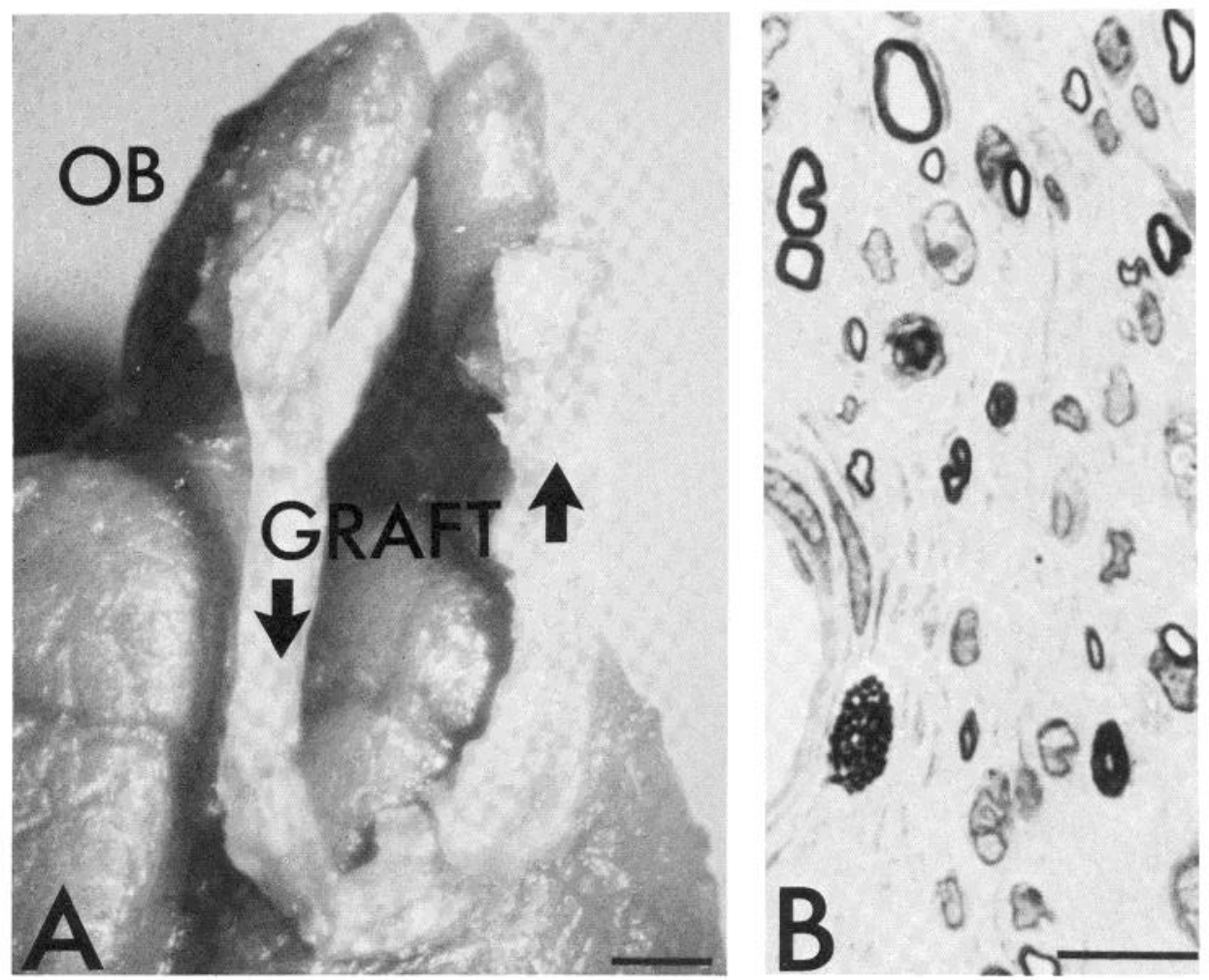

HRP-labeled neurons in 14 of the 30 bulbs. The average number $( \pm$ SE) of labeled cells in each bulb was $24( \pm 6)$ with a range of 3 to 76. Of the 351 neurons labeled in 14 OBs examined, 345 were mitral and 6 were tufted cells. These two cell types were identified from their characteristic shape, large diameter (12 to $30 \mu \mathrm{m}$ ), and location in the mitral cell or external plexiform and glomerular layers (Fig. 4). No periglomerular, short axon, or granule cells were retrogradely labeled in these experiments. All the labeled mitral and tufted cells were distributed in a narrow territory near the graft tip (Fig. 5). For these dorsally placed grafts, the labeled cells were confined to the dorsal half of the $\mathrm{OB}$ within a territory that extended $2 \mathrm{~mm}$ in front and $1.2 \mathrm{~mm}$ behind the center of the graft tip (Fig. 5). The majority of the labeled cells $(93 \%)$ were at or rostral to the graft, and only $7 \%$ were located caudally (Fig. 6). The length of the mitral and tufted cell axons within these PNS grafts, estimated as the distance between the site of HRP application and the intrabulbar tip of the graft, ranged from 0.5 to $1 \mathrm{~cm}$.

\section{Double labeling with fluorescent dyes}

In these experiments, designed to investigate if the $\mathrm{OB}$ axons that grow along nerve grafts originate from damaged mitral cells, we made the following observations.

The grafting procedure causes a focal loss of neurons. There were many TB-labeled neurons throughout the $\mathrm{OB}$ in rats examined 2 to 6 months after grafting, when TB was applied to the LOT within 2 days of sacrifice (Fig. 7). However, there were also well-circumscribed areas, neighboring the graft tip, where cells were lost or atrophic and few neurons were labeled with TB (Fig. 7). The mitral cell loss was confined to an approximately $2-\mathrm{mm}$-wide zone around the graft tip (Fig. 8). Many surviving mitral cells within these areas of $\mathrm{OB}$ cell loss were retrogradely labeled from the graft (Fig. 10A). The size and position of the areas that contained lost cells and neurons labeled from the graft with fluorescent dyes were similar to the territories occupied by the mitral cells labeled in the experiments where HRP was the tracer (Fig. 8).

Only a small number of mitral cells appears to project to both the graft and the LOT. In group I, of 10 grafted OBs examined 2 to 6 months after grafting, $94 \pm 3 \%$ (Table I) of the cells labeled from the graft 4 days before sacrifice were not subsequently labeled by a different dye applied to the LOT 2 d later (Fig. 9). Because an average of only $6 \%$ of the cells whose axons regenerated into grafts were doubly labeled, we concluded that neurons with such dual projections were rare and that the majority of the $\mathrm{OB}$ neurons with axons in the graft lost their fibers in the LOT.

Mitral cells damaged within the $O B$ regrow axons along PNS grafts. In 6 grafted OBs from the group II experiments, most mitral cells were labeled from the LOT by TB applied immediately after grafting; however, the majority $(81 \pm 7 \%$ ) (Table I) of neurons subsequently labeled with NY from the graft were singly labeled by NY and did not contain TB in their cytoplasm (Fig. 10). These findings suggest that, although the majority of mitral cell axons are not severed by the grafting procedure and can be retrogradely labeled from the LOT, most neurons which later innervate the grafts lose their axons in the LOT at the time of grafting. The remaining JY-labeled mitral cells also contained TB (Fig. 10). These doubleabeled neurons may be cells with projections into both graft and LOT (Fig. 1), the former branch likely arising by growth of an axon collateral from a damaged neuron or by sprouting from uninjured neurons. The incidence of these double-labeled cells must be, however, interpreted cautiously because diffusion of TB cannot be prevented in experiments where the tissues are exposed to this dye for such lengthy times (3 to 6 weeks) (O'Leary et al., 1981).

The combined damage caused by grafting into the $O B$ and sectioning the LOT on the same day did not appear to have enhanced or diminished the number of mitral cells that grew axons along PNS grafts. In group II, although only some fibers were damaged by the insertion of the graft, nearly all of the projection axons were cut in the LOT on the day of grafting (Fig. 1). Nevertheless, the average number and distribution of the cells labeled from the graft in this group of experiments, $25( \pm 12)$, were similar to those after application of HRP to the peripheral end of the graft in animals where the LOT remained intact $24( \pm 6)$. This finding sug. gests that collaterals close to the somata of mitral cells (Kishi et al., 1984) were not stimulated to grow into grafts by the severance of their main axonal projection through the LOT (Fig. 1), a response that might be expected from the enhanced growth into PNS grafts 


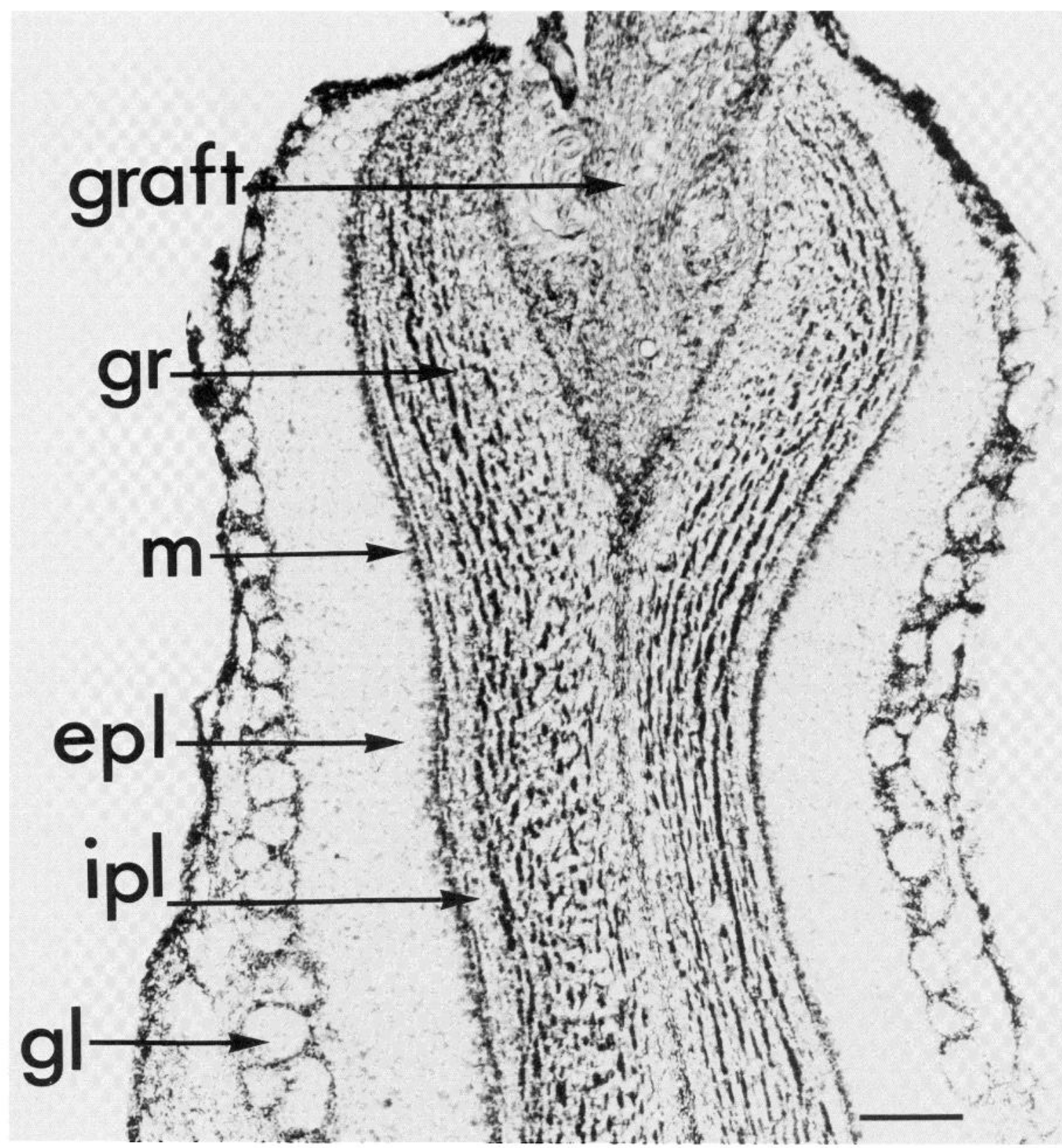

Figure 3. Coronal section of grafted OB. OB projection neurons are located in the mitral cell layer (mitral cells) and in external plexiform and glomerular layers (tufted cells). Graft tip is $1 \mathrm{~mm}$ deep and traverses through each of the layers of the OB. The glomerular and plexiform layers adjacent to the graft are shrunken. $g r$, granule cell layer; $m$, mitral cell layer; $i p l$, internal plexiform layer; epl, external plexiform layer; $g$, glomerular layer. Bar, $200 \mu \mathrm{m}$.

of the central processes of dorsal root ganglion cells after transection of their peripheral processes (Richardson and Issa, 1984).

Controls. In three animals, the possibility of spurious neuronal labeling was investigated by the serial application of two different fluorescent dyes (TB and NY) to the peripheral stump of crushed and uncrushed grafts bridging between the two OBs. Only $2 \%$ of the mitral cells were doubly labeled when the second dye was applied shortly after crushing the graft; $78 \%$ of labeled neurons in OBs with uncrushed grafts contained both TB and NY. These findings suggest the labeling of $\mathrm{OB}$ cells requires axonal continuity from the graft tip to the bulb.

We also tested the ability of the fluorescent dye (TB) to retrogradely label most mitral cells by applying TB persistently for 3 weeks to the transected LOT and comparing the population of labeled cells with that of cells found after counterstaining the same sections with thionin. In three OBs (10 sections examined in each bulb), the average ratios ( \pm SE) of TB to thionin stained mitral cells were $0.93 \pm 0.04,1.13 \pm 0.05$, and $1 \pm 0.001$, an indication that a prolonged application of TB to the LOT results in the labeling of the great majority of the mitral cells. The distribution of nonfluorescent cells was also determined from examination of the counterstained sections with epifluroescence. Although much of the fluorescence was leached out by counterstaining, it was still possible to distinguish labeled cells. An average of eight nonfluorescent thionin-stained cells per section was found in 10 sections. These cells were widely distributed in the mitral cell layer and not clustered in any one quadrant. This suggests that labeling failures are rare after prolonged application of TB to the LOT (Table I).

\section{Technical considerations}

Many of this study's conclusions depend on the reliability of the retrograde tracing methods used to identify the cells of origin of the axons that grow into these peripheral nerve grafts. As in previous investigations (David and Aguayo, 1981; Benfey and Aguayo, 1982; 

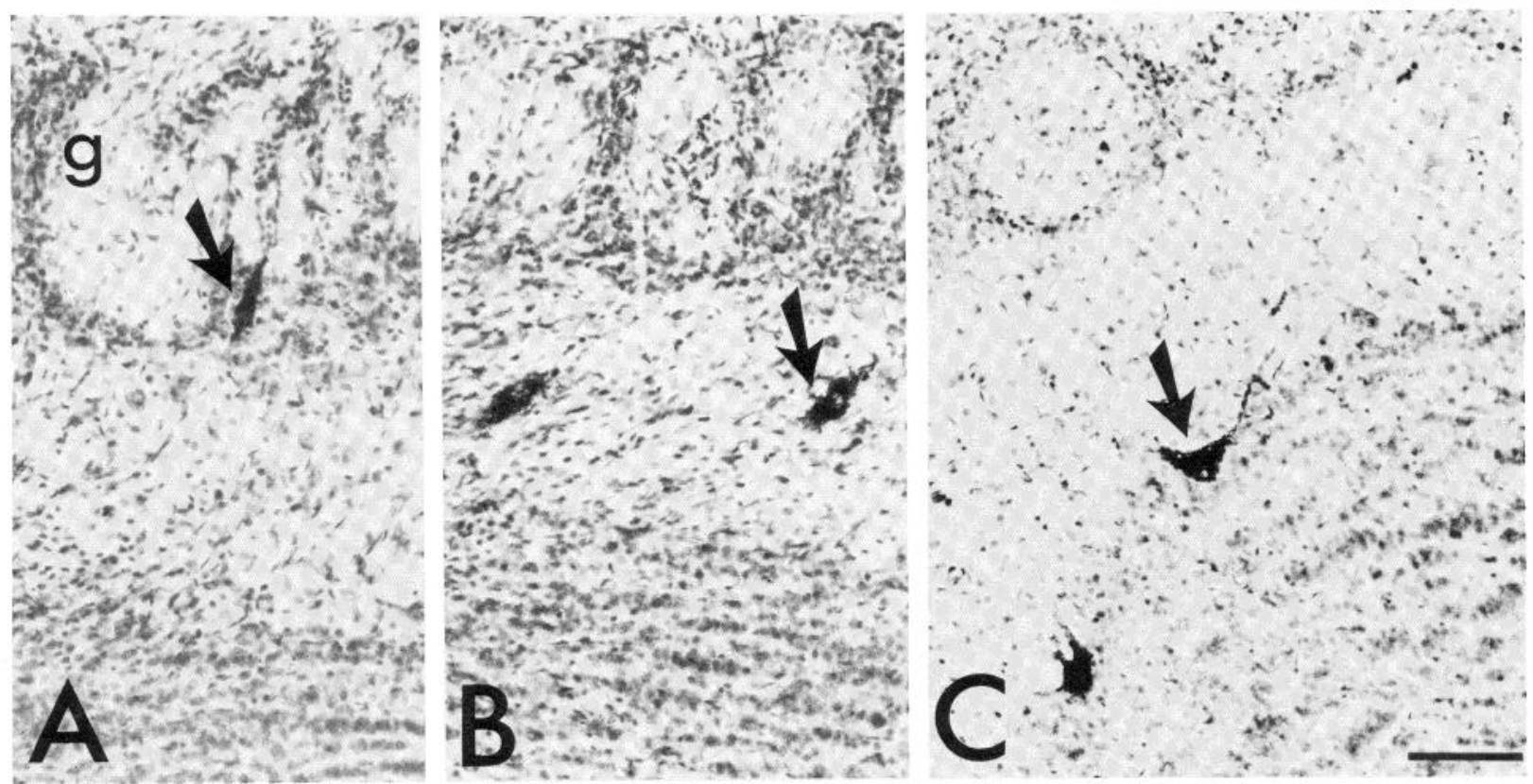

Figure 4. Coronal sections through OB after HRP application to a peripheral nerve graft implanted for 2 months. Retrogradely labeled bulbar neurons are filled with reaction product; examples at arrows $(40-\mu \mathrm{m}$ coronal sections counterstained with thionin). $A$, HRP-labeled external tufted cell in the glomerular layer $(g)$. B, Labeled middle tufted cells in the external plexiform layer. $C$, Labeled mitral cells. Bar, $100 \mu \mathrm{m}$ for $A, B$, and $C$.

Figure 5. "Unfolded" map of the mitral cell layer (see Devor, 1976a) for three grafted OBs (R90, R120, R128) illustrating the position of the HRP labeled mitral cells (R90, $n=76$; R120, $n=123 ; \mathrm{R} 128, n=$ 7). Most labeled neurons are close to graft tips (shaded areas) and in the dorsal half of the $\mathrm{OB}$, represented here by the 2 middle quadrants of the map. $a$, anterior; $p$, posterior; $d m$, dorsomedial; $d l$, dorsolateral; $v m$, ventromedial; vl, ventrolateral. Bar, $1 \mathrm{~mm}$.

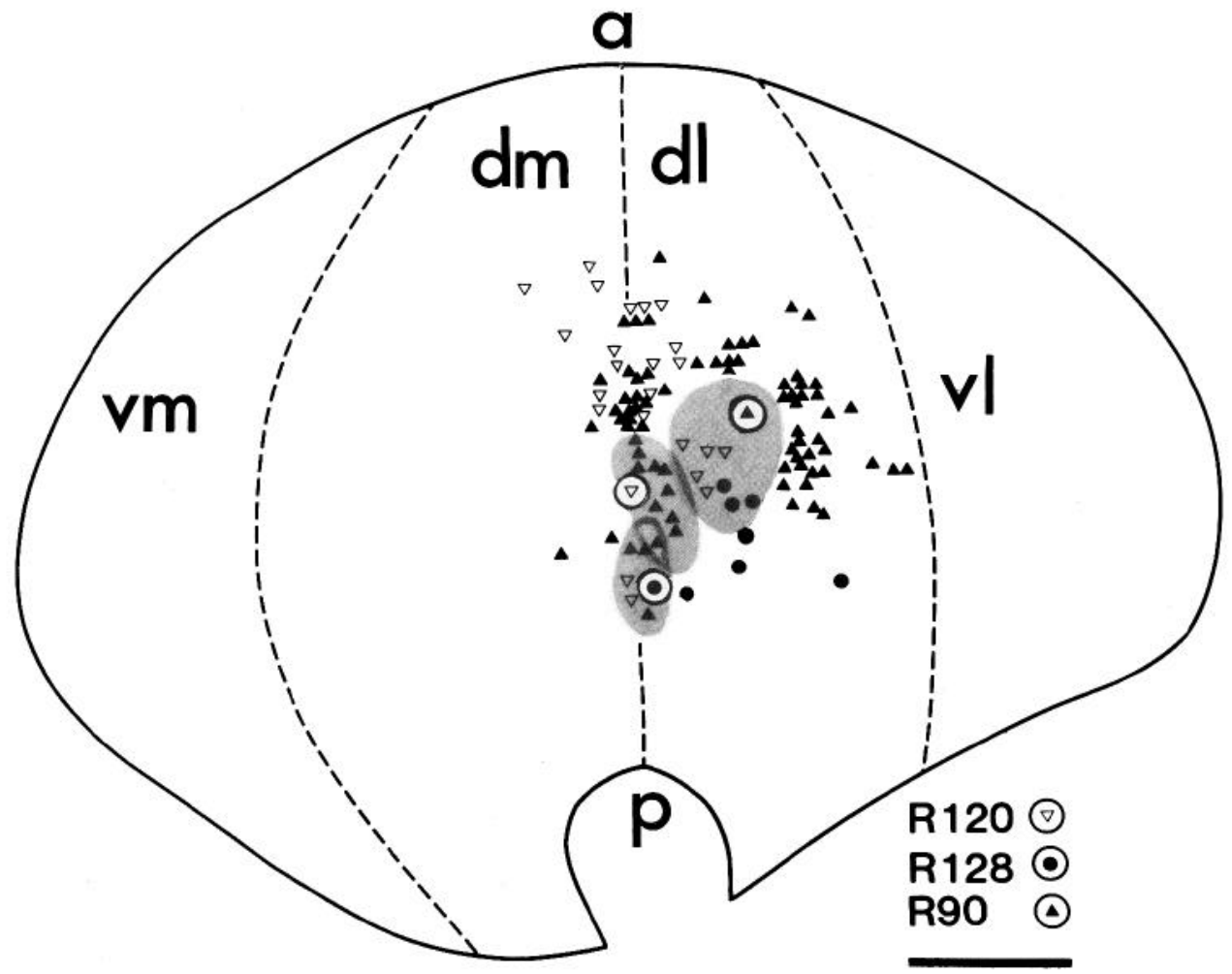

Richardson et al., 1982), we have found that the structural continuity of the graft is required for the labeling of $\mathrm{OB}$ neurons by retrograde tracers applied to the peripheral tip of the graft. The selective labeling of mitral and tufted cells located in the dorsal portion of the $\mathrm{OB}$ also suggests that the labels are transported retrogradely along $O B$ axons in the graft; spurious labeling by diffusion through nonneuronal tissues or by haematogenous spread would have resulted in a more generalized labeling of many types of bulbar neurons.

We have also concluded that most neurons singly labeled from the graft were axotomized on the day of grafting and that the severance of their axons prevented retrograde labeling by prolonged application of the tracer to the LOT. The alternative explanation of a technical failure of labeling of OB neurons by the TB applied to the LOT is not likely for three reasons: (1) most mitral cells are labeled by tracers applied to the anterior piriform cortex even after short dye application times (Luskin and Price, 1982); (2) the arrangement of mitral cell axons in the LOT ensures that axons from neurons that innervate grafts inserted into the dorsal half of the bulb would be in contact with the tracer applied to the LOT; these axons course dorsolaterally within the LOT (Shepherd and Haberly, 1970) and lie 


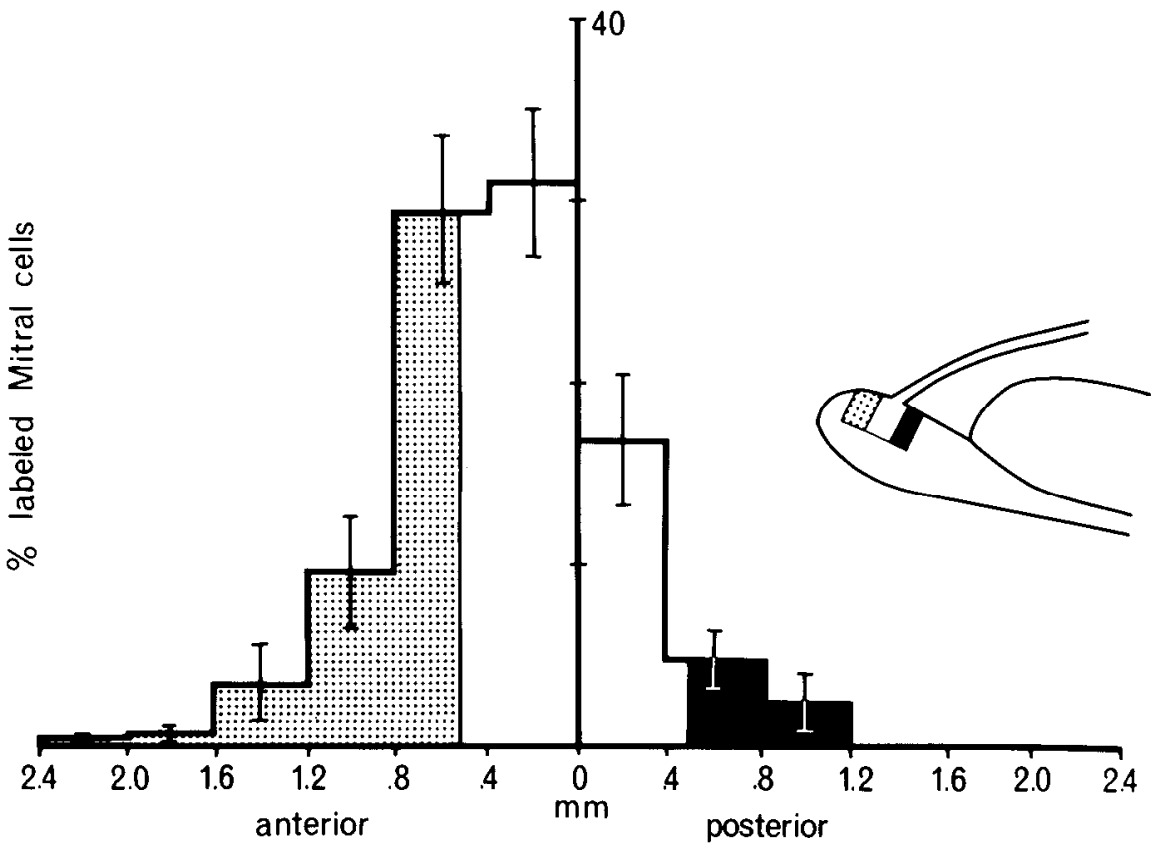

Figure 6. Distribution of 345 HRP-labeled neurons along the anteroposterior axis of 12 grafted OBs. Of these cells, $93 \%$ are located at or anterior to the center of the graft (clear and stippled portion of the histogram). In each grafted $\mathrm{OB}$, labeled mitral cells were counted in 400- $\mu \mathrm{m}$ sectors and the sums expressed as a percentage of the total cells labeled in that bulb. Vertical columns represent the mean percentage $( \pm$ $\mathrm{SE}$ ) of all labeled cells located at comparable levels in 12 grafted OBs.

within the portion of the LOT we use for the application of the tracer; (3) in our control experiments nearly $100 \%$ of the mitral cells in the normal $\mathrm{OBs}$ examined were retrogradely labeled after prolonged application of TB to the LOT; the few labeling failures were not concentrated in any particular part of the $\mathrm{OB}$. In contrast, in grafted OBs, neurons not labeled from the LOT but labeled from the graft were clustered in the dorsum of the $\mathrm{OB}$.

\section{Discussion}

These studies indicate that mitral and tufted neurons of the adult rat $\mathrm{OB}$ share with other nerve cells of the brain and spinal cord a capacity to rogrow axons of considerable length. This potential for renewed axonal growth is expressed when these cells interact with non-neuronal components of peripheral nerve contained within denervated PNS grafts (Aguayo et al., 1981). Although the molecular basis of this regenerative response remains unknown, there is increasing evidence that a combination of neuronal properties and environmental conditions ultimately determines its success or failure. The present study indicates the following four neuronal conditions bear a relationship to the regrowth of OB axons into PNS grafts: (1) cell type; (2) distance between nerve cell somata and the site of injury; (3) the course of axonal projections and their relation to the site of injury and grafting; and (4) neuronal damage.

Cell type. Of the five different types of neurons whose somata are in the $\mathrm{OB}$, only mitral and tufted cells regenerated axons into these PNS grafts. Although there are more tufted than mitral cells (Allison and Warwick, 1949; Grafe, 1983), most regenerated axons arise from mitral cells. The lower incidence of axonal regrowth from tufted cells is another example of heterogeneity in the response of different neurons to axonal injury (Aguayo et al., 1983). In the OB, other characteristics distinguish mitral and tufted cells; the latter are smaller, have shorter axonal processes, and may contain substance P (Schneider and Scott, 1983; Macrides and Schneider, 1982; Davis et al., 1982; Burd et al., 1982), but there is no indication that any of these attributes have a bearing on their individual responses to injury. Of additional interest is that two of the cells that innervated these grafts were external tufted cells whose projections are thought to be restricted to the OB or retrobulbar areas (Schneider and Scott, 1983). On the other hand, axonal regrowth was not demonstrated for any of the local circuit neurons whose projections are also confined to the OB (Price and Powell, 1970a, b; Shepherd, 1972). These small cells with either short or no axons may degenerate and die after injury or be unable to lengthen their processes to reach the site where the label is applied to the graft. It has recently been documented that olfactory receptor neurons located in the nasal mucosa grow axons into PNS grafts inserted directly into the nasal sensory epithelium (Barber, 1982). It is unknown, however, if such axons arise from damaged neurons or from newly formed cells of this continuously dividing neuronal population (Graziadei and Graziadci, 1980). We have not investigated the regrowth of such receptor neurons into these PNS grafts placed in the OB.

Distance between neuronal somata and site of injury. Previous studies demonstrated that the innervation of grafts inserted into small lesions in the CNS arose mainly from neurons within a few $\mathrm{mm}$ of the site of injury and grafting (David and Aguayo, 1981; Benfey and Aguayo, 1982; Richardson et al., 1982). More distant nerve cells, situated several centimeters away, may innervate grafts in larger lesions which interrupt long descending and ascending spinal tracts (Richardson et al., 1984). In the OB only nerve cells within 2.5 $\mathrm{mm}$ of the graft tip regrew their axons and thus grafts inserted in the dorsal $\mathrm{OB}$ were innervated exclusively by dorsal projection neurons, while those neurons in the ventral region of the $\mathrm{OB}$ regrew axons into grafts implanted ventrally (unpublished observations). The clumped distribution of labeled mitral and tufted neurons at and in front of the graft tip indicates that each graft induces axonal growth from a restricted population of nearby olfactory projection cells. This effect could be mediated by the release of trophic molecules with limited penetration into the injured OB but most likely relates to the damage of the axons of these projection neurons.

The course of axonal projections and their relation to the site of injury and grafting. The caudal direction of the axons of mitral and tufted neurons, which leave the OB through the LOT (Shepherd and Haberly, 1970; Price and Sprich, 1975; Kishi el al., 1984), appears to influence the probability of axonal damage and regrowth. Because most labeled cells lie near and rostral to the graft, their main axons can be assumed to have passed through the site of grafting on their course towards the LOT and thus have been severed; the axons of neurons caudal to the graft would course away from the graft and likely not be damaged.

Neuronal damage. Perhaps the most important finding of this study is the indication that bulbar projection neurons that are axotomized by the grafting procedure appear to be the main source of axon growth along PNS grafts. Indeed, after PNS graft insertion, most mitral cells with axons in the graft no longer project along the LOT. This loss is likely due to an early axotomy and not to a gradual axonal retraction because the application of TB to the LOT on the 

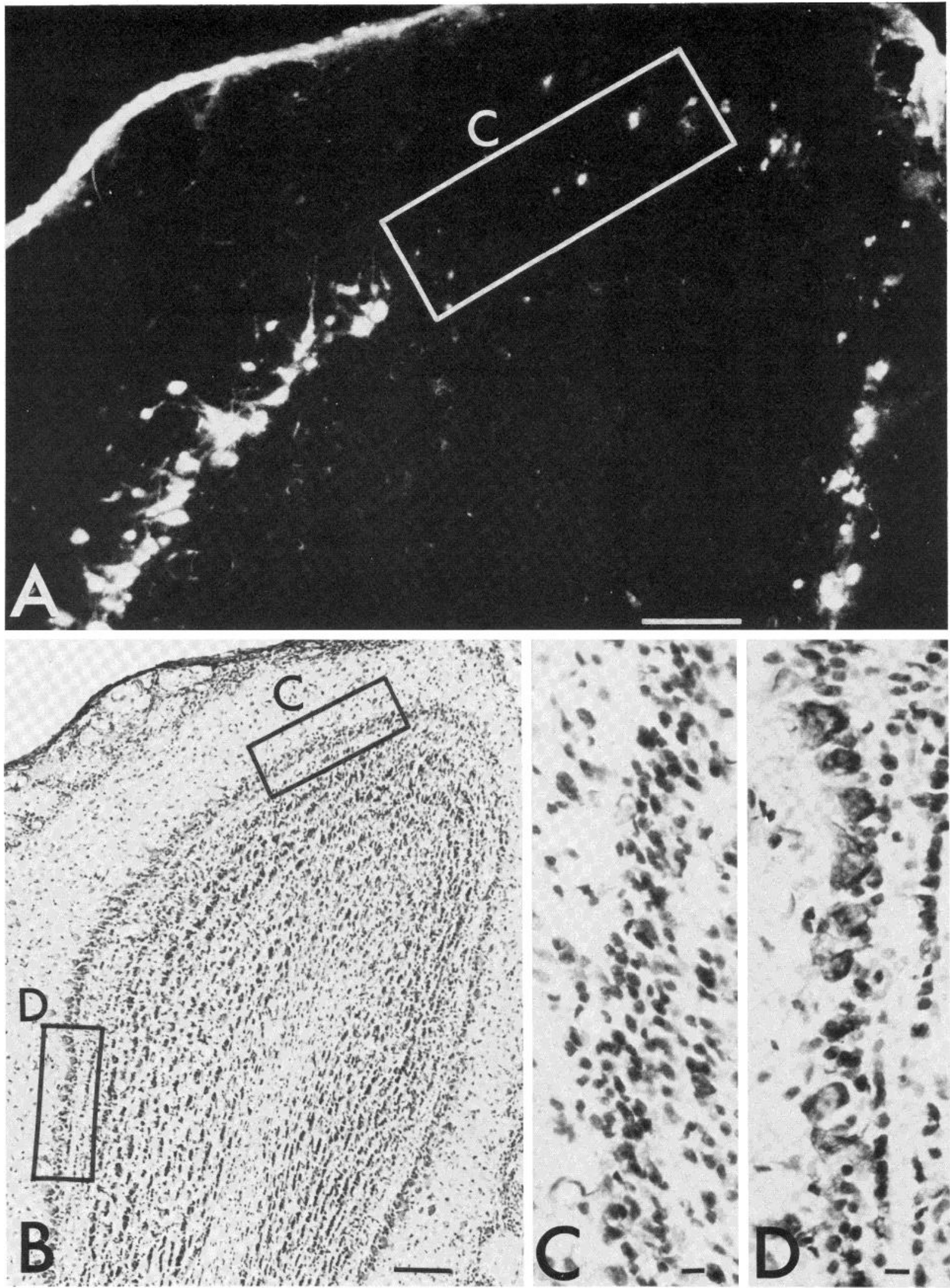

Figure 7. Coronal section of $\mathrm{OB}$, anterior to the site of grafting, viewed with epifluorescence $(A)$ and bright field optics $(B, C$ and $D)$. Gaps in fluorescent labeling of the mitral cell layer reflect mitral cell loss. A, TB-labeled mitral cells 2 days after the application of TB to the LOT. A white box surrounds a zone wih few fluorescent mitral cells. Bar, $100 \mu \mathrm{m}$. B. Thionin counterstain of section in A. Box C in the dorsal part of the OB corresponds to outlined area in $A$. Bar, $100 \mu \mathrm{m}$. C. Higher magnification of inset $C$ illustrates the marked loss of stained mitral cells. Bar, $10 \mu \mathrm{m}$. $D$, higher magnification of normal row of mitral cells found within inset D. Bar, $10 \mu \mathrm{m}$. 

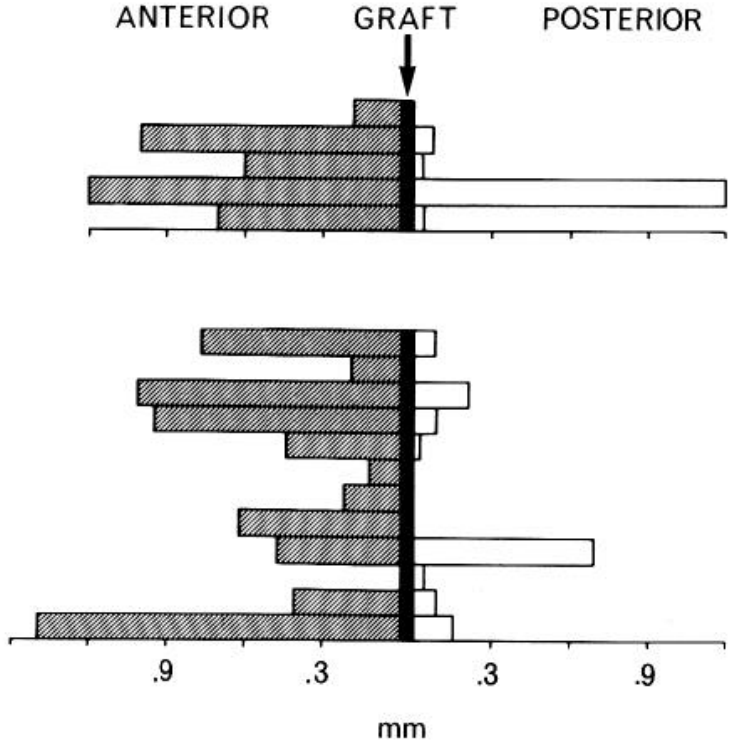

Figure 8. Comparison of anteroposterior distribution of mitral cell loss (top) and labeled mitral cells (bottom) with respect to the tip of the graf (indicated by $y$ axis). The $x$ axis denotes the maximal distance to either the anterior or posterior edge of the graft tip. Top, The mitral cell loss in most grafted OBs is anterior to the graft (shaded bars) ( $n=5$ grafted OBS). Bottom, The distribution of HRP-labeled mitral cells in 12 grafted OBs overlaps that of mitral cell loss shown in top graph.

day of grafting, as well as several months later, failed to retrogradely label the majority of neurons that innervate the graft. Axon regeneration from axotomized neurons explains the localization and the types of changes we observed in the OB: (1) those cells whose axons project through the sites of graft insertion are axotomized; (2) some axotomized neurons undergo retrograde degeneration and die while others survive and regrow axons that extend the length of the PNS grafts; (3) a third group of surviving neurons may fail to regenerate long fibers because they do not establish direct contact with critical components of the PNS contained within the grafts (Aguayo et al., 1983). The retraction of injured axonal stumps and a local proliferation of CNS glia may further contribute to isolate axonal growth cones from the PNS grafts (Aguayo et al., 1983; Richardson et al., 1984).

The extension of axon collaterals along PNS grafts from OB neurons with intact LOT axons occurs rarely, judging from the small number of neurons that were doubly labeled by different fluorescent dyes applied to the graft and the LOT. This suggests that axon sprouting from uninjured nerve cells is not an important source of innervation of these grafts. Furthermore, although sprouting of uninjured collaterals after a more distal interruption of the main axon (the "pruning effect") has been reported in the developing hamster olfactory tract (Devor, 1976b), in our experiments the transection of the LOT on the day of grafting (group II; "Materials and Methods") did not seem to enhance the innervation of the graft; the average number of labeled neurons was similar to that in grafted OBs with intact LOTs. Recently, extensive fiber regeneration has been observed in axotomized retinal ganglion cells (So and Aguayo, 1985). Indirect support for axonal regrowth from damaged neurons has also been obtained in the rat after hemisection (Richardson et al., 1984) or complete transection of the spinal cord (Richardson et al., $1980,1982)$ where fibers that were probably cut in ascending and desending long tracts in the dorsal and lateral spinal columns were shown to innervate PNS grafts. Furthermore, the innervation of PNS transplants by the spinal processes of dorsal root ganglia is markedly enhanced by the transection of the peripheral axons of these cells (Richardson and Issa, 1984). Finally, studies using HRP and fluorescent dyes applied after the crushing of fibers that had already grown across PNS "bridges" joining the medulla oblongata and spinal cord
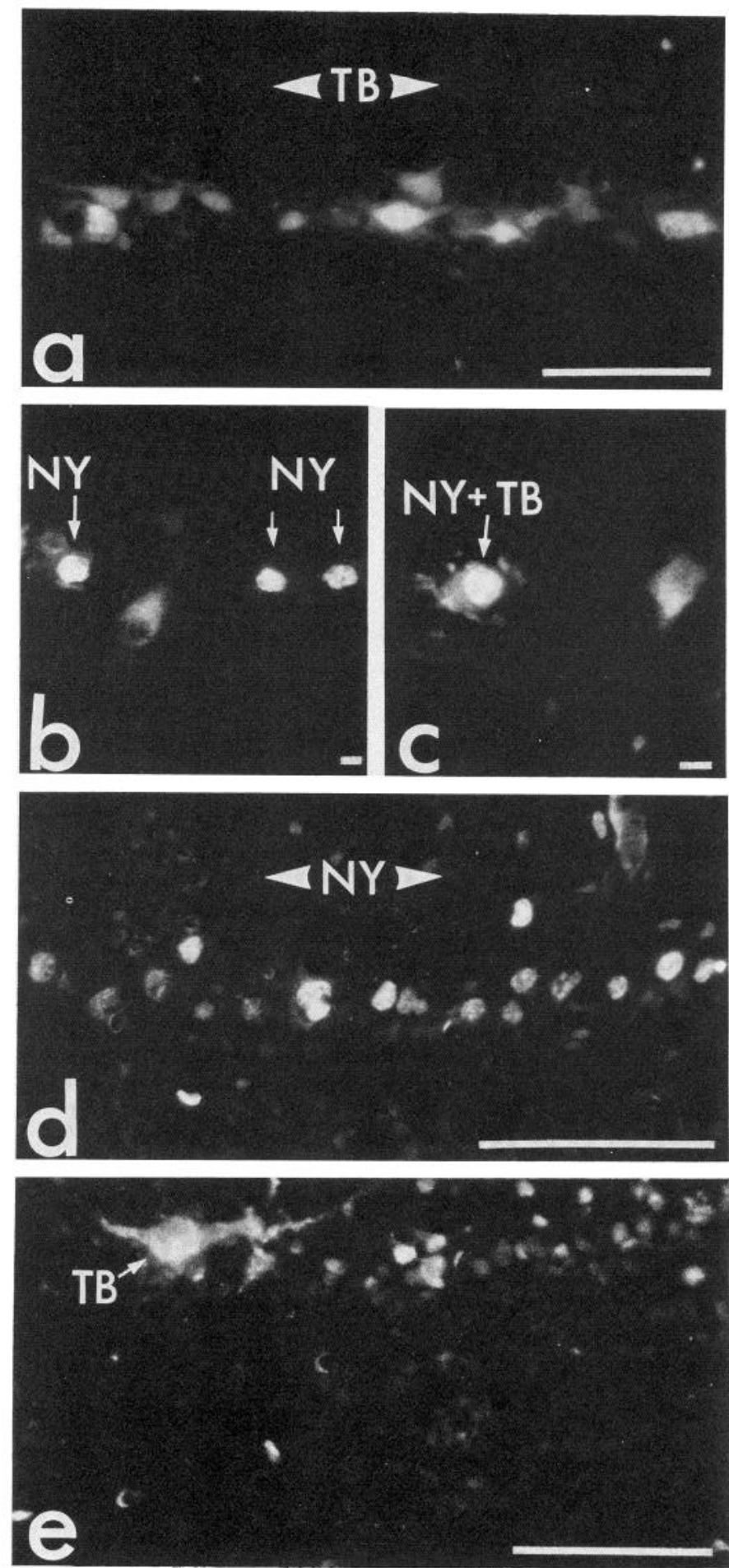

Figure 9. Labeling of mitral cells from the graft and/or the LOT (group experiments). A, Row of mitral cells labeled by application of TB to the LOT 2 days prior to sacrifice. Bar, $100 \mu \mathrm{m}$. B, Row of mitral cells singly labeled from application of NY to the graft, 4 days prior to sacrifice. Bar, $10 \mu \mathrm{m}$. A TB neuron-labeled only from the LOT is in the middle of this row. C, Doublelabeled mitral cells after application of NY to the graft and TB to the LOT. Bar, $10 \mu \mathrm{m}$. D, Row of mitral cells singly labeled by NY application to the LOT. Bar, $100 \mu \mathrm{m}$. E, Mitral cell labeled only by TB applied to the graft is located in a row of cells labeled with NY applied to the LOT. Note gap to left of TB cell demonstrating concomitant loss of mitral cells in this region. (Bar, $100 \mu \mathrm{m})$. 

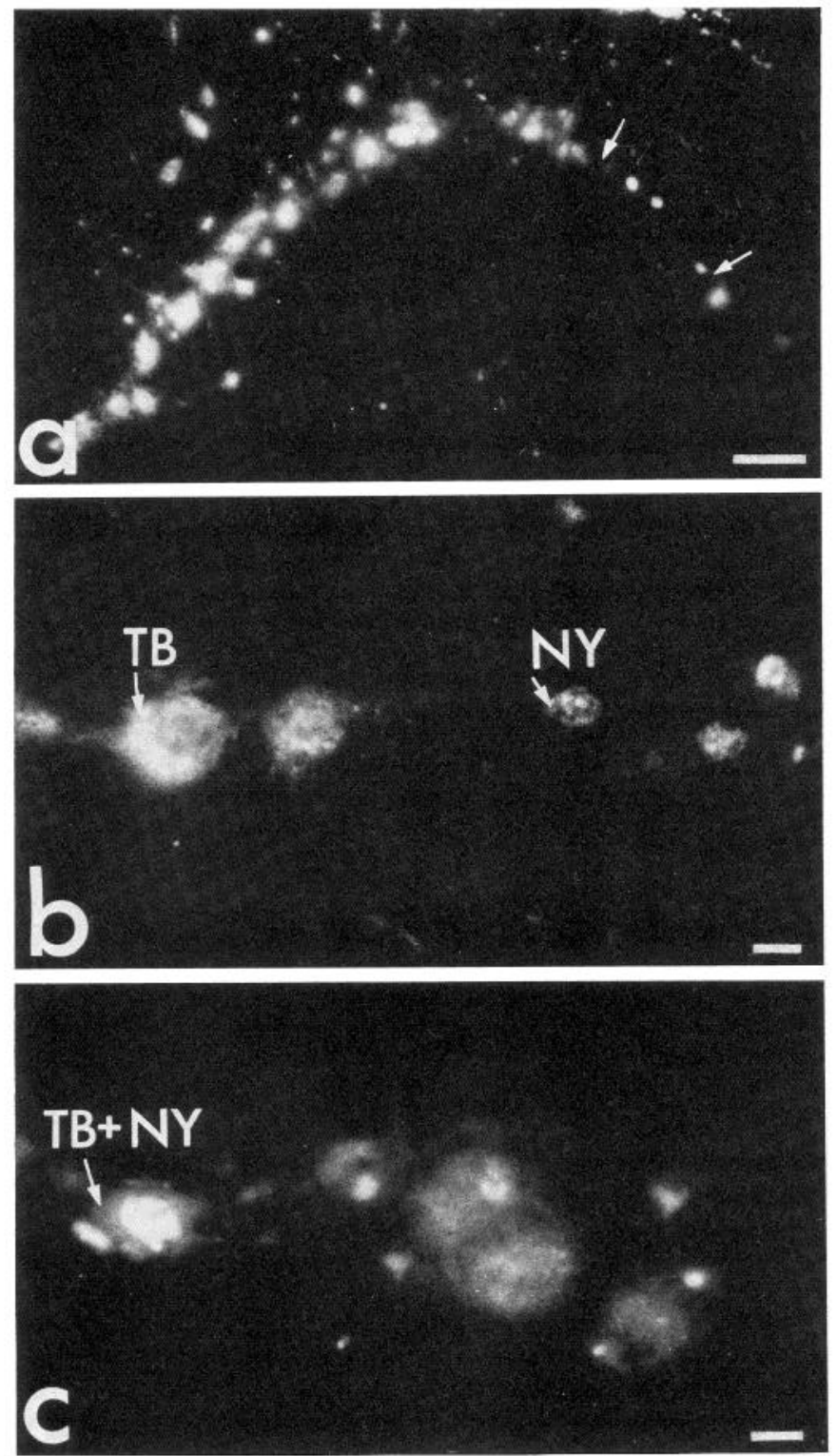

Figure 10. Two stage labeling of mitral cells projecting to the graft and LOT (group II experiments). TB was applied to the LOT on the day of grafting, NY to the graft $2 \mathrm{~d}$ before sacrifice. $A$, Most mitral cells project axons into the LOT and are labeled by TB. Cells projecting axons only into the graft are singly labeled by NY and lie in a zone where there are few TB cells (between arrows). Bar, $100 \mu \mathrm{m}$. B, Mitral cells singly labeled from the graft (NY cells) near cells projecting axons exclusively into the LOT (TB-labeled cells). Bar, $10 \mu \mathrm{m}$. $C$, Double labeled $(T B+N Y)$ mitral cell adjacent to neurons labeled with TB. Bar, $10 \mu \mathrm{m}$.

(David and Aguayo, 1985) suggest that central axons are not only capable of growth after injury in the CNS but may regenerate again after damage in the graft.

The successful regeneration of OB axons along PNS grafts contrasts with their failure to regrow in the absence of PNS grafts after injury in the mature animal (Devor, 1976b; Caviness et al., 1977). Interestingly, $\mathrm{OB}$ efferents severed in newborn hamsters may grow across a transected LOT (Devor, 1976b; Grafe, 1983). Because other central axons of mature rats have been reported to lengthen across transplanted fetal brain tissue (Kromer et al., 1980 for a review, see Björklund and Stenevi, 1984) it is conceivable that both immature CNS glia and non-neuronal components of denervated adult peripheral nerve share certain effects on axonal growth.

The nature of most interactions between neurons and their envi-
TABLE I

Fluorescent dye labeling of $\mathrm{OB}$ neurons projecting axons to the graft and or the LOT

Shown for group I is the number of OB neurons labeled in each grafted bulb with fluorescent dyes applied to the graft and the LOT several months after grafting. Most neurons projecting to the graft are singly labeled. Shown for group ॥ are the OB neurons labeled with TB applied to the LOT immediately after graft insertion and then labeled from the graft with NY 3 to 6 weeks later. Most neurons projecting to the graft are not labeled by the early application of dye to the LOT, an indication that they are axotomized at the time of grafting.

\begin{tabular}{cccc}
\hline Group I & $\begin{array}{c}\text { Single Labled } \\
\text { from Graft }\end{array}$ & $\begin{array}{c}\text { Double Labeled } \\
\text { from Graft }\end{array}$ & $\begin{array}{c}\text { Percentage of } \\
\text { Single Labeled }\end{array}$ \\
\hline 2 & 1 & 67 \\
& 6 & 0 & 100 \\
& 2 & 0 & 100 \\
& 8 & 1 & 89 \\
& 27 & 2 & 93 \\
& 75 & 0 & 100 \\
& 10 & 1 & 91 \\
& 19 & 0 & 100 \\
6 & 0 & 100 \\
& 46 & 0 & 100 \\
& 63 & 23 & $94 \pm 3^{b}$ \\
& 10 & 4 & 73 \\
& 15 & 12 & 51 \\
& 17 & 0 & 100 \\
& 5 & 0 & 100 \\
& 5 & 1 & 83 \\
& & & $81 \pm 7^{b}$ \\
\hline
\end{tabular}

${ }^{a}$ Proportion of single to total number of neurons labeled retrogradely from the graft.

${ }^{b}$ Mean \pm SEM.

ronment in the injured CNS and PNS remains unknown. Stimulatory and inhibitory effects could depend on the release of specific molecules by the graft or the injured tissues (Varon et al., 1981; Richardson and Ebendal, 1982) and surface properties of the ensheathing cells (Bunge and Bunge, 1978; Lander et al., 1982). The present findings suggest that the regenerative response of mitral, tufted, and probably other CNS neurons requires a concomitant intrinsic challenge, here induced by axotomy. Thus, a combination of neuronal properties and extrinsic conditions must determine the extent and localization of some of the responses to injury observed in the $\mathrm{OB}$ and other regions of the brain and spinal cord. It cannot be excluded that different experimental conditions may result in a greater regrowth from uninjured nerve cells.

\section{References}

Aguayo, A. J., R. Dickson, J. Trecarten, M. Attiwell, G. M. Bray, and P. M. Richardson (1978) Ensheathment and myelination of regenerating PNS fibers by transplanted optic nerve glia. Neurosci. Lett. 9: 97-104.

Aguayo, A. J., S. David, P. M. Richardson, and G. M. Bray (1981) Influences of the glial environment on the elongation of axons after injury transplantation studies in adult rodents. J. Exp. Biol. 95: 231-240.

Aguayo, A. J., S. David, P. M. Richardson, and G. M. Bray (1982a) Axonal elongation in peripheral and central nervous system transplants. In Advances in Cellular Neurobiology, S. Fedoroff and L. Hertz, eds., pp. 215234, Academic Press, New York.

Aguayo, A. J., P. M. Richardson, S. David, and M. Benfey (1982b) Transplantation of neurons and sheath cells-a tool for the study of regeneration. In Repair and Regeneration of the Nervous System, J. G. Nicholls, ed., pp. 91-105, Springer-Verlag, New York.

Aguayo, A. J., M. Benfey, and S. David (1983) A potential for axonal regeneration in neurons of the adult mammalian nervous system. In Nervous System Regeneration, B. Haber, J. R. Perez-Polo, G. A. Hashim and A. M. G. Stella, eds., pp. 327-340, Alan R. Liss, New York.

Aguayo, A. J., A. Bjorklund, U. Stenevi, and T. Carlstedt (1984) Fetal 
mesencephalic neurons extend long axons across PNS grafts inserted in the adult rodent striatum. Neurosci. Lett. 45: 53- 58.

Allison, A. C., and R. T. T. Warwick (1949) Quantitative observations of the olfactory system of the rabbit. Brain 72: 186-197.

Barber, P. C. (1982) Regeneration of olfactory sensory axons into trans. planted segments of peripheral nerve. Neuroscience 7(11): 2677-2785.

Benfey, M., and A. J. Aguayo (1982) Extensive elongation of axons from rat brain into peripheral nerve grafts. Nature 296: 150-152.

Benfey, M., U. R. Buenger, M. Vidal-Sanz, G. M. Bray, and A. J. Aguayo (1985) Axonal regeneration from GABAergic neurons in the adult rat thalamus. J. Neurocytol., in press.

Bentivoglio, M., H. G. J. M. Kuypers, C. E. Catsman-Berrevoets, and O. Dann (1979) Fluorescent retrograde neuronal labelling in rat by means of substances binding specifically to adenine-thymine rich DNA. Neurosci. Lett. 12: 235-240.

Björklund, A., and U. Stenevi (1984) Intracerebral neural implants: neuronal replacement and reconstruction of damaged circuitries. Annu. Rev. Neurosci. 7: 279-308.

Bray, G. M., M. Benfey, U. Buenger, M. Vidal-Sanz, and A. J. Aguayo (1985) Regenerative responses of GABAergic neurons after PNS grafting into rat thalamus. In Neural Grafting in the Mammalian CNS, A. Björklund and U. Stenevi, eds., Fernström Foundation Series, Vol. 5, Elsevier, Amsterdam, in press.

Buenger, U., and A. J. Aguayo (1983) Rat visual system neurons grow axons along PNS grafts. Soc. Neurosci. Abstr. 9: 699

Bunge, R. P., and M. B. Bunge (1978) Evidence that contact with connective tissuc matrix is required for normal interaction between Schwann cells and nerve fibers. J. Cell Biol. 78: 943-950.

Burd, G., B. J. Davis, and F. Macrides (1982) Ultrastructural evidence of substance $P$ immunoreactive neurons in the main olfactory bulb of the hamster. Neuroscience 7(11): 2697-2704.

Cajal, R. Y. (1928) Degeneration and Regeneration of the Nervous System Hafner Publishing Co., New York. Reprinted 1959

Caviness, V. S., M. G. Korde, and R. S. Williams (1977) Cellular events induced in the molecsllar layer of the piriform cortex by ablation of the olfactory bulb in the mouse. Brain Res. 134: 13-34.

David, S., and A. J. Aguayo (1981) Axonal elongation in peripheral nervous system "bridges" after central nervous system injury in adult rats. Science 214: $931-933$

David, S., and A. J. Aguayo (1985) Axonal regeneration after crush injury of rat central nervous system innervating peripheral nerve grafts. J. Neurocytol. 14: 1-12.

Davis, B. J., G. D. Burd, and F. Macrides (1982) Localization of metenkephalin, substance $P$, and somatostatin immunoreactivities in the main olfactory bulb of the hamster. J. Comp. Neurol. 204: 377-383.

Devor, M. (1976a) Fiber trajectories of olfactory bulb efferents in the hamster J. Comp. Neurol. 166: 31-48.

Devor, M. (1976b) Neuroplasticity in the rearrangement of olfactory tract fibers after neonatal transection in hamsters. J. Comp. Neurol. 166: 4972

Edds, M. V. (1953) Collateral nerve regeneration. Dev. Biol. 28: 260-276.

Grafe, M. J. (1983) Developmental factors affecting regeneration in the central nervous system: Early but not late formed mitral cells reinnervate olfactory cortex after neonatal tract section. J. Neurosci. 3: 617-630.

Graziadei, P. P. C. and G. A. Monti-Graziadei (1980) Neurogenesis and neuron regeneration in the olfactory system of mammals. Il. Deafferentation and reinnervation of the olfactory bulb following section of the fila olfactoria in the rat. J. Neurocytol. 9: 145-162.

Haberly, L. B., and J. L. Price (1978) The axonal patterns of the mitral and tufted cells of the olfactory bulb in the rat. Brain Res. 129: 152-157.

Jeffrey, G., A. Cowey, and H. G. J. M. Kuypers (1981) Bifurcating retinal ganglion cell axons in the rat demonstrated by retrograde double labelling. Exp. Brain Res. 44: 34-40.

Kishi, K., K. Mori, and H. Ojima (1984) Distribution of local axon collaterals of mitral, displaced mitral, and tufted cells in the rabbit olfactory bulb. J. Comp. Neurol. 225: 511-526

Kromer, L. F., A. Björklund, and U. Stenevi (1980) Innervation of embryonic hippocampal implants by regenerating axons of cholinergic septal neurons in the adult rat. Brain Res. 210: 155-171

Kuypers, H. G. J. M., M. Bentivoglio, C. E. Catsman-Berrevoets, and A. T. Bharos (1980) Double retrograde neuronal labelling through divergent axon collaterals using two fluorescent tracers with the same excitation wave- length which label different features of the cell. Exp. Brain Res. 40: 383392

Lander, A. D., D. K. Fuijii, D. Gospodarowicz, and L. F. Reichardt (1982) Characterization of a factor that promotes neurite outgrowth: evidence linking activity to a heparan sulfate protcoglycan. J. Cell Biol. 94: 574585.

Luskin, M. B., and J. L. Price (1982) The distribution of axon collaterals from the offactory bulb and the nucleus of the horizontal limb of the diagonal band to the olfactory cortex demonstrated by double retrograde labelling techniques. J. Comp. Neurol. 209: 249-263.

Macrides, F., and S. P. Schneider (1982) Laminar organization of mitral and tufted cells in the main olfactory bulb of the adult hamster. J. Comp. Neurol. 208: 419-430

Mesulam, M. M. (1978) Tetramethylbenzidine for horseradish peroxidase neurohistochemistry: a non-carcinogenic blue reaction product with superior sensitivity for visualizing neuronal afferents and efferents. J. Histochem. Cytochem. 26: 106-117.

Munz, M., M. Rasminsky, A. J. Aguayo, M. Vidal-Sanz, and M. Devor (1985) Functional activity of rat brainstem neurons regenerating axons along peripheral nerve grafts. Brain Res., in press.

O'Leary, D. D. M., B. B. Stanfield, and W. M. Cowan (1981) Evidence that the early postnatal restriction of the cells of origin of the callosal projection is due to the elimination of axonal collaterals rather than to the death of neurons Dev. Brain Res. 1: 607-617.

Powell, T. P. S., W. M. Cowan, and G. Raisman (1965) The central offactory connexions. J. Anat. 99: 781-813.

Price. J. L., and T. P. S. Powell (1970a) The morphology of the granule cells in the olfactory bulb. J. Cell. Sci. 7: 91-123.

Price, J. L., and T. P. S. Powell (1970b) The mitral and short axon cells of the olfactory bulb. J. Cell Sci. 7: 631-651.

Price, J. L., and W. W. Sprich (1975) Observations on the lateral olfactory tract of the rat. J. Comp. Neurol. 162: 321-336

Purves, D., W. Thompson, and J. W. Yip (1981) Reinnervation of ganglia transplanted to the neck from different levels of the guinea pig sympathetic chain. J. Physiol. (Lond.) 313: 49-63.

Raisman, G. (1977) Formation of synapses in the adult rat after injury: similarities and differences between a peripheral and a central nervous system site. Philos. Trans. R. Soc. Lond. (Biol.) 278: 349-359.

Richardson, P. M., U. M. McGuinness, and A. J. Aguayo (1980) Axons from CNS neurons regenerate into PNS grafts. Nature 284: 264-265.

Richardson, P. M., and T. Ebendal (1982) Nerve growth activities in rat peripheral nerve. Brain Res. 246: 57-64.

Richardson, P. M., U. M. McGuinness, and A. J. Aguayo (1982) Peripheral nerve autografts to the rat spinal cord: Studies with axon tracing methods. Brain Res. 237: 147-162.

Richardson, P. M., V. M. K. Issa, and A. J. Aguayo (1984) Regeneration of long spinal axons in the rat. J. Neurocytol. 13: 165-182

Richardson, P. M., and V. M. K. Issa (1984) Peripheral injury enhances regeneration of spinal neurons. Nature 309: 791-792.

Sawchenko, P. E., and L. W. Swanson (1981) A method for tracing biochemically defined pathways in the central nervous system using combined fluorescence retrograde transport and immunohistochemical techniques. Brain Res. 210: 31-51

Schneider, S. P., and J. Scott (1983) Orthodromic response properties of rat olfactory bulb mitral and tufted cells correlate with their projection patterns. J. Neurophysiol. 50: 358-378.

Shepherd, G. M., and L. B. Haberly (1970) Partial activation of olfactory bulb: analysis of field potentials and topographic relation between the olfactory bulb and the lateral olfactory tract. J. Neurophysiol. 33: 643-653.

Shepherd, G. M. (1972) Synaptic organization of the mammalian olfactory bulb. Physiol. Rev. 52: 864-917.

So, K. - F., and A. J. Aguayo (1985) Lengthy regrowth of cut axons from ganglion cells after peripheral nerve transplantation into the retina of adult rats. Brain Res. 328: 349-354.

Sperry, R. W. (1941) The effect of crossing nerve to antagonistic muscles in the hindlimb of the rat. J. Comp. Neurol. 75: 1-19.

Varon, S., S. D. Skaper, and M. Manthrope (1981) Trophic activities of dorsal root and sympathetic ganglionic neurons in media conditioned by Schwann and other peripheral nerve cells. Dev. Brain Res. 1: 73-87.

Vidal-Sanz, M., M. Rasminsky, and A. J. Aguayo (1984) Anatomical and functional studics of axonal regeneration from neurons in the somatosensory cortex of the adult rat. Soc. Neurosci. Abstr. 10: 1025.

Weinberg. E. L., and P. S. Spencer (1979) Studies on the control of myelinogenesis. 3. Signalling of oligodendrocyte myelination by regenerating peripheral axons. Brain Res. 162: 273-279. 